Full Length Article

\title{
Pilot-scale study on NO emissions from coarse coal combustion preheated by circulating fluidized bed
}

\author{
Shujun Zhu ${ }^{\mathrm{a}, \mathrm{b}, *}$, Jianguo $\mathrm{Zhu}^{\mathrm{a}, \mathrm{c}}$, Qinggang Lyu ${ }^{\mathrm{a}, \mathrm{c}}$, Jingzhang Liu ${ }^{\mathrm{a}}$, Ziqu Ouyang \\ ${ }^{a}$ Institute of Engineering Thermophysics, Chinese Academy of Sciences, Beijing 100190, China \\ ${ }^{\mathrm{b}}$ State Key Laboratory of High-temperature Gas Dynamics, Institute of Mechanics, Chinese Academy of Sciences, Beijing 100190, China \\ ${ }^{\mathrm{c}}$ University of Chinese Academy of Sciences, Beijing 100049, China
}

\section{A R T I C L E I N F O}

\section{Keywords:}

Pilot-scale

Coarse coal combustion

NO emissions

Preheating

Circulating fluidized bed

\begin{abstract}
A B S T R A C T
Achieving stable low- $\mathrm{NO}_{x}$ combustion of coarse pulverized coal could improve the energy efficiency of the combustion system. In this study, a pilot-scale experiment on coarse coal (0-1 mm) combustion preheated by circulating fluidized bed is conducted. The coarse coal could achieve a long-term stable preheating, and the assisted combustion by the high-calorific preheated coal gas $\left(3.06 \mathrm{MJ} / \mathrm{Nm}^{3}\right)$ and the higher physical sensible heat $\left(754{ }^{\circ} \mathrm{C}\right)$ greatly improved the ignition performance and the combustion stability of the preheated fuel. Meanwhile, the release ratio of fuel-nitrogen during the preheating was $36.56 \%$, while the concentrations of $\mathrm{NO}_{x}$ in the preheated coal gas were all 0 ppm. During the stable combustion, the volume-based average temperature and the volume-based temperature fluctuation coefficient in the main combustion zone was approximately $1112{ }^{\circ} \mathrm{C}$ and $8.89 \%$, and the combustion efficiency was approximately $95 \%$. The $\mathrm{NO}_{x}$ concentrations in the strong reductive zone were almost $0 \mathrm{ppm}$. As the reaction atmosphere along the combustion path gradually varied from reducing to oxidizing, fuel-nitrogen was mainly oxidized to NO, and the NO emissions was approximately 68 ppm $\left(114 \mathrm{mg} / \mathrm{m}^{3} @ 6 \% \mathrm{O}_{2}\right)$. In addition, the effects of burnout air positions in strong reductive zone on NO emissions could be ignored.
\end{abstract}

\section{Introduction}

Coal energy is the most important component in the world's energy [1]. According to the BP Statistical Review of World Energy (2019), coal consumption rate increased by $1.4 \%$ in 2018 , which is twice the average growth rate in the past decade. In China, the proportion of coal consumption in total energy consumption is as high as $60.22 \%$ in 2018 , and this state will not change for a long time. Currently, one of the main coal utilization modes is combustion, and the most important equipment for coal combustion is the pulverized coal boiler. The coal particle size used in pulverized coal boilers in power plants and industries is relatively fine, usually less than $0.1 \mathrm{~mm}[2,3]$. This is because the coarser coal particles may have problems such as difficulties in ignition, unstable combustion, and low burnout efficiency during the combustion $[4,5]$. However, with the coal particle size being coarser, the mechanical and electrical consumption of the associated coal mill would decrease and the wear would be reduced, which have a series of benefits such as decreasing the regular maintenance costs and power consumption [6], and improving the safety and stability of the mill system. These factors ultimately lead to improvements in the power efficiency and economic benefits [7]. Therefore, achieving stable and efficient combustion of coarse pulverized coal will further improve the energy efficiency of the combustion system.

In addition to the above problems of unstable combustion and poor burnout encountered by the coarse coal combustion, it also faces the problem of high pollutant emissions, especially the emissions of nitrogen oxides $\left(\mathrm{NO}_{x}\right)$. This is due to the complex chemical reactions associated with $\mathrm{NO}_{x}$ and the seriousness of the hazards, such as it is one main source of haze [8]. In China, the standard (GB13223-2011) for $\mathrm{NO}_{x}$ emitted from coal combustion in power plants in key areas is set at $50 \mathrm{mg} / \mathrm{m}^{3}\left(@ 6 \% \mathrm{O}_{2}\right)$. At present, the low- $\mathrm{NO}_{x}$ combustion technology is designed with the principle of more uniform combustion reactions and lower combustion temperature $[9,10]$. However, when the coal particle size becomes coarse, it is possible to maintain high combustion efficiency only by increasing the combustion temperature in a conventional combustion mode. This in turn lead to an exponential increase in the emissions of thermal-NO, which causes more serious environmental pollution. And, Kamar et al. indicates that the coarser coal combustion would generate higher NO emissions [11]. Therefore, this factor of high- $\mathrm{NO}_{x}$ combustion also greatly limits the combustion application of coarse pulverized coal.

\footnotetext{
* Corresponding author at: Institute of Engineering Thermophysics, Chinese Academy of Sciences, Beijing 100190, China.

E-mail address: zhushujun@iet.cn (S. Zhu).
} 
In this study, the promising technology of pulverized coal combustion preheated by circulating fluidized bed is adopted to break above limitations. During the coal combustion, the pre-circulating fluidized bed (PCFB) is used as a burner, and the main combustion reactions are completed in the post-combustion chamber (PCC) $[12,13]$. The combustion temperature is controlled below $1300{ }^{\circ} \mathrm{C}$, and the coal burned out within a reasonable combustion temperature range.

In lab-scale experiments, the feasibility and superiority of this combustion technology have been verified on $30 \mathrm{~kW}_{\text {th }}$ test platforms [12]. The previous studies indicates that the improved physical sensible heat of fuel and the chemical conversions from the ternary solid phase to the binary gas-solid phase greatly improve the combustion stability and burnout. And the strong reducing atmosphere during the preheating is the most key factor to achieving low- $\mathrm{NO}_{x}$. However, limited by the equipment size and the heat capacity, the solid-gas mass ratio in the PCFB (approximately 0.31 ) is significantly lower than that in the actual design and operation (0.70-0.80). In addition, the main combustion zone is so small that the flow field and the gas concentration field cannot be fully expanded, which makes the reaction process deviate from the actual operation process. In other words, the experimental study on $30 \mathrm{~kW}_{\text {th }}$ test platform mainly obtained trending results. To verify the technique route and obtain more reliable experimental data, the pilot-scale study need to be carried out. Therefore, we conducted the coarse coal combustion experiments on $0.2 \mathrm{MW}_{\text {th }}$ test platform.

Compared with $30 \mathrm{~kW}_{\text {th }}$ test platform, the size and structure of PCFB on $0.2 \mathrm{MW}_{\text {th }}$ test platform is similar, but the combustion zone in 0.2 $\mathrm{MW}_{\text {th }}$ PCC is more bigger. This means that the solid-gas mass ratio in the PCFB could be increased to approximately 0.77 , and the main combustion reaction zone becomes bigger where the internal flow field is more uniform and the chemical reactions are more sufficient. The fuel-nitrogen migration and transformation law in the combustion chamber is closer to the actual engineering application. In the previous study on $0.2 \mathrm{MW}_{\text {th }}$ test platform [14], the coal particle size distribution was less than $0.1 \mathrm{~mm}$, while the operational stability of the coarse particles was not studied. And the previous research focused on the coal combustion characteristics, while the nitrogen oxides $\left(\mathrm{NO}_{x}\right)$ distribution law was unclear in the combustion system, especially in the preheating.

In summary, this study will conduct a pilot-scale preheating combustion experiment on coarse coal particles $(0-1 \mathrm{~mm})$ : a more detailed analysis on the preheating process and the combustion process, with particular attention to the fuel-nitrogen migration and transformation. Then, we explore the effects of burnout air distribution on NO emissions during the coarse coal combustion. The research content will provide a new approach for coarse coal combustion, and provide theoretical guidance for future engineering applications.

\section{Experimental}

\subsection{Test platform}

The test platform (Fig. 1) consists mainly of a pre-circulating fluidized bed (PCFB), a post-combustion chamber (PCC) and the auxiliary equipment. The combustion process is briefly described as follows: firstly, the primary air of low air-equivalent ratio carries pulverized coal into the PCFB for partial pyrolysis and gasification. Then, the hightemperature gas-solid mixture (defined as high-temperature preheated fuel) from the cyclone flows into the PCC through the connecting pipe, and the combustion reactions proceed from the top to the bottom in the combustion chamber.

The PCFB is designed to operate at a temperature range of $800-1000{ }^{\circ} \mathrm{C}$ and it is made of $\mathrm{Cr} 25 \mathrm{Ni} 20$ steel. The height and the inner diameter of the riser are $1000 \mathrm{~mm}$ and $149 \mathrm{~mm}$ respectively, and the diameter of the cyclone is $149 \mathrm{~mm}$. The structure of the returner is $\mathrm{U}$ shaped, which ensures the normal circulation by adjusting the loose air and the return air separately. Four K-type thermocouples are arranged at $50 \mathrm{~mm}, 500 \mathrm{~mm}, 950 \mathrm{~mm}$ above the bottom of riser and the returner, respectively. Furthermore, a pressure measuring point is arranged at the bottom of riser to monitor the operational stability of the PCFB, and a K-type thermocouple is arranged at the cyclone outlet to monitor the temperature of the high-temperature preheated fuel.

The PCC is designed to operate at a temperature range of $1000-1300{ }^{\circ} \mathrm{C}$. The inner structure of the combustion chamber is cylinder, and the furnace side wall is layered by refractory material and heat insulating material. The height and the inner diameter of the PCC are $6000 \mathrm{~mm}$ and $700 \mathrm{~mm}$ respectively. The secondary air nozzle is arranged on the PCC top: the high-temperature preheated fuel flows into the PCC through the central pipe at central location, and the secondary air flows into the PCC through the four air pipes at ring-shaped locations. Seventeen S-type thermocouples are arranged at each $300 \mathrm{~mm}$ from $150 \mathrm{~mm}$ to $3150 \mathrm{~mm}$ and each $500 \mathrm{~mm}$ from $3500 \mathrm{~mm}$ to $6000 \mathrm{~mm}$ below the PCC top. In addition, a pressure measuring point is arranged at $150 \mathrm{~mm}$ below the PCC top to monitor the operation stability of the combustion chamber.

The auxiliary system is mainly composed of a coal feeding system, an air supply system and a flue gas treatment system. The coal feeding mode adopts the air direct blowing, and the primary air carrying coal particles is directly sent into the riser. The air supply system includes a blower and an induced draft fan. The blower supplies the primary air, the secondary air, the burnout air and the cooling air, wherein the secondary air flows into the PCC top and the burnout air is arranged at ten locations with each $300 \mathrm{~mm}$ from $300 \mathrm{~mm}$ to $3000 \mathrm{~mm}$ below the PCC top. In order to ensure that the combustion temperature does not exceed $1300{ }^{\circ} \mathrm{C}$, four air cooling casings are suspended from the PCC top, and the heated air is directly discharged to the atmosphere. The flue gas led out by the induced draft fan flows to the atmosphere through the cooling water system, the bag filter and the chimney. A flue gas sampling point is arranged on the pipe between the cooling water system and the bag filter, where the tail flue gas component is also defined as the flue gas component at $6000 \mathrm{~mm}$ below the PCC top.

The technical properties of the main measurement devices are summarized in Table 1.

\subsection{Experimental conditions}

The fuel used in this study is a typical Chinese bituminous coal (Shenmu bituminous coal), and its proximate and ultimate analyses are summarized in Table 2. The coal particle size distribution ranges from 0 to $1 \mathrm{~mm}$, with the particle size at a cumulative volume fraction of $50 \%$ $\left(d_{50}\right)$ and $90 \%\left(d_{90}\right)$ being $0.118 \mathrm{~mm}$ and $0.386 \mathrm{~mm}$.

The ratios of the each-stage air flow rate to the air flow rate for the stoichiometric complete combustion are defined as the air-equivalent ratios of the primary air $\left(\lambda_{\mathrm{PA}}\right)$, the secondary air $\left(\lambda_{\mathrm{SA}}\right)$ and the burnout air $\left(\lambda_{\mathrm{BA}}\right)$. And the ratio of the total air flow rate to the air flow rate for the stoichiometric complete combustion is defined as the total airequivalent ratio ( $\lambda_{\text {stoic }}$ ). The definition is summarized as follows:

$\lambda_{\mathrm{PA}}=\frac{A_{\mathrm{PA}}}{A_{\text {Stoic }}}$

$\lambda_{\mathrm{SA}}=\frac{A_{\mathrm{SA}}}{A_{\mathrm{Stoic}}}$

$\lambda_{\mathrm{BA}}=\frac{A_{\mathrm{BA}}}{A_{\mathrm{Stoic}}}$

$\lambda_{\text {Stoic }}=\lambda_{\mathrm{PA}}+\lambda_{\mathrm{SA}}+\lambda_{\mathrm{BA}}$

where $A_{\text {Stoic }}\left(\mathrm{Nm}^{3} / \mathrm{h}\right)$ is the air flow rate for stoichiometric complete combustion, $A_{\mathrm{PA}}$ is the primary air flow rate flowing into the PCFB, $A_{\mathrm{SA}}$ and $A_{\mathrm{BA}}$ are the secondary air flow rate and the burnout air flow rate flowing into the PCC.

During the stable operation, the coal feeding rate was 


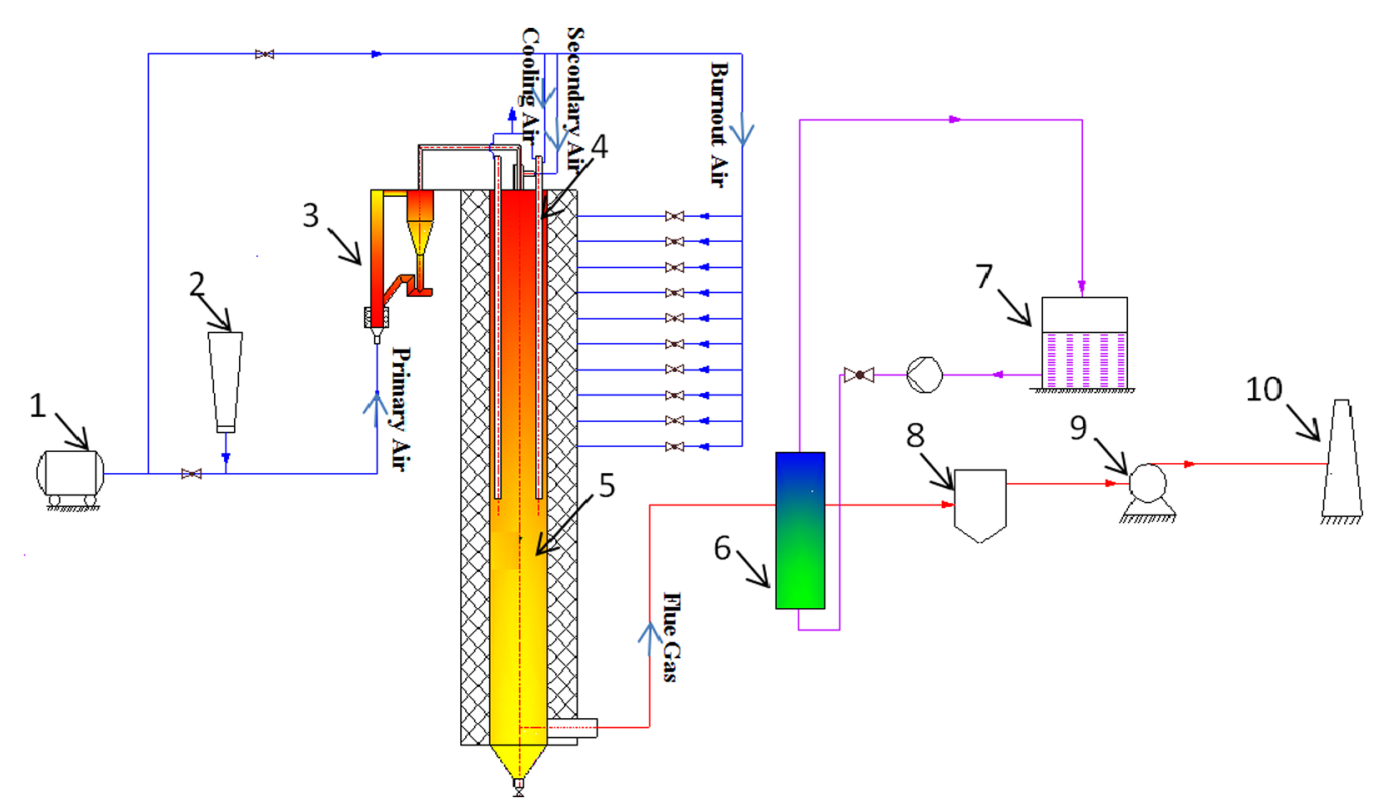

Fig. 1. Schematic diagram of test platform (1, air compressor; 2, coal feeder; 3, pre-circulating fluidized bed; 4, air cooling casing; 5, post-combustion chamber; 6 , water cooler; 7, water tank; 8, bag filter; 9, induced draft fan; 10, chimney).

approximately $25.11 \mathrm{~kg} / \mathrm{h}$, and the thermal power of the test platform was approximately $0.17 \mathrm{MW}_{\mathrm{th}}$. The oxygen concentration in the tail flue gas (defined as $O_{\mathrm{FG}}$ ) was approximately $2.74 \%$. More detailed experimental parameters are summarized in Table 3.

\section{Results and discussion}

In this section, we will summarize and analyze the preheating characteristics in PCFB and the combustion characteristics in PCC. Then, we will discuss the effects of burnout air distribution on the combustion characteristics in PCC.

\subsection{Preheating characteristics in PCFB}

Fig. 2(a) shows the temperature distribution in PCFB and Fig. 2(b) shows the pressure distribution at the bottom of riser during the stable long-term operation $(820 \mathrm{~min})$. When the air-equivalent ratio of the primary air was 0.17 , the time-based average temperature in the PCFB was $852{ }^{\circ} \mathrm{C}$, and the temperature difference among all temperature measuring points was less than $40{ }^{\circ} \mathrm{C}$, which indicates the fluidization was uniform. In addition, the pressure at the bottom of riser was stable at $0.54-0.74 \mathrm{kPa}$ along time, which also verified the stability of the preheating. The pressure measurement values at about $380 \mathrm{~min}$ deviated significantly from the normal pressure fluctuation value. This is because there was a bend in the pressure extraction tube at the time. After reprocessing, the pressure measurement returned to normal. In summary, the coarse pulverized coal can achieve a long-term stable preheating process.
Table 2

Proximate and ultimate analyses (wt.\%, air-dried) of fuel.

\begin{tabular}{lllllllllll}
\hline \multicolumn{1}{c}{ Proximate analysis } & \multicolumn{4}{c}{ Ultimate analysis } & & \multicolumn{2}{l}{$\begin{array}{l}\text { Lower heating } \\
\text { value }\end{array}$} \\
\hline$M$ & $A$ & $V M$ & $F C$ & $C$ & $H$ & $N$ & $S$ & $O^{\mathrm{a}}$ & $Q_{\text {net,ar }}(\mathrm{MJ} / \mathrm{kg})$ \\
\hline 8.12 & 7.68 & 31.89 & 52.31 & 72.31 & 4.93 & 0.85 & 0.30 & 5.81 & 24.43 \\
\hline
\end{tabular}

${ }^{\mathrm{a}}$ By difference.

Table 3

Experimental operating parameter.

\begin{tabular}{lllllll}
\hline $\begin{array}{l}\text { Coal feeding rate } \\
(\mathrm{kg} / \mathrm{h})\end{array}$ & $\begin{array}{l}\text { Thermal power } \\
\left(\mathrm{MW}_{\mathrm{th}}\right)\end{array}$ & $\lambda_{\mathrm{PA}}$ & $\lambda_{\mathrm{SA}}$ & $\lambda_{\mathrm{BA}}$ & $\lambda_{\mathrm{Stoic}}$ & $\mathrm{O}_{\mathrm{FG}}(\%)$ \\
\hline 25.11 & 0.17 & 0.17 & 0.40 & 0.56 & 1.13 & 2.50 \\
\hline
\end{tabular}

A sampling port is arranged at the cyclone outlet to sample the hightemperature preheated fuel, which consists of the high-temperature preheated coal gas and the preheated char. The gas chromatographic analyzer and the TESTO-350 gas analyzer were used to measure the preheated coal gas components, and the results are summarized in Table 4 . The oxygen concentration in the coal gas was $0 \%$, indicating the preheating was in a strong reducing atmosphere. Moreover, the combustible components in the coal gas mainly included CO $(8.27 \%)$, $\mathrm{H}_{2}(9.15 \%)$ and $\mathrm{CH}_{4}(2.86 \%)$, and the lower heating value of the coal gas was as high as $3.06 \mathrm{MJ} / \mathrm{Nm}^{3}$. Compared to the solid-fuel combustion, the reaction intensity and reaction rate are greater in the gas-fuel

Table 1

Technical property of measurement device.

\begin{tabular}{|c|c|c|c|}
\hline Device & Type & Property & Sensibility \\
\hline Thermocouples in PCFB & K-type (Ni-Cr/Ni-Si) & $0-1100{ }^{\circ} \mathrm{C}$ & $\pm 0.5 \% \mathrm{FS}$ \\
\hline Micro-pressure transmitter in PCFB & B0300 & $0-3.5 \mathrm{kPa}$ & $\pm 0.5 \% \mathrm{FS}$ \\
\hline Thermocouples in PCC & S-type (Pt/Pt-Rh) & $0-1600{ }^{\circ} \mathrm{C}$ & $\pm 0.5 \% \mathrm{FS}$ \\
\hline Gas analyzer & TESTO-350 & $\mathrm{NO}, \mathrm{NO}_{2}, \mathrm{~N}_{2} \mathrm{O}$ & $\pm 1.4 \%$ \\
\hline Coal gas analyzer & Agilent 3000A & $\mathrm{CO}_{2}, \mathrm{CO}, \mathrm{CH}_{4}, \mathrm{H}_{2}, \mathrm{O}_{2}, \mathrm{~N}_{2}$ & $\pm 1 \%$ \\
\hline Thermogravimetric analyzer & STA 449 F3 NETZSCH & / & / \\
\hline Gas analyzer & Gasmet FTIR DX-4000 & $\mathrm{CO}_{2}, \mathrm{CO}, \mathrm{NO}, \mathrm{N}_{2} \mathrm{O}, \mathrm{NH}_{3}, \mathrm{HCN}$ & $\pm 2 \%$ \\
\hline Oxygen analyzer & CYZC Zirconia & $\mathrm{O}_{2}: 0-21 \%$ & $\pm 2 \%$ \\
\hline
\end{tabular}




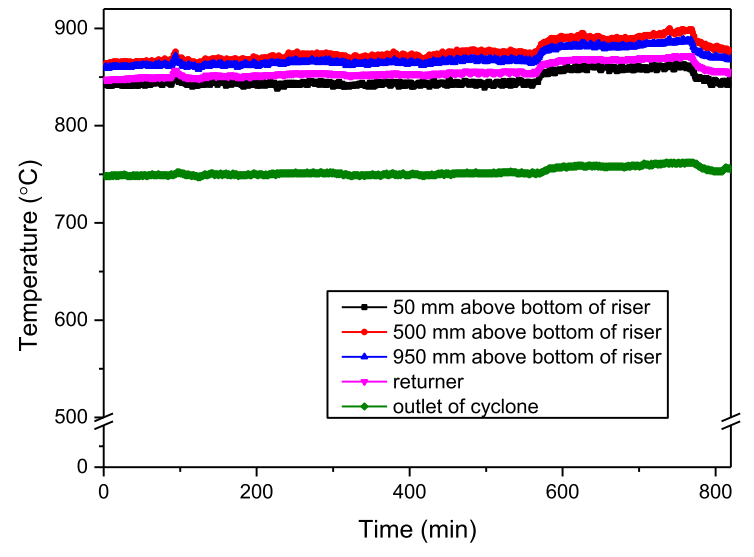

(a)

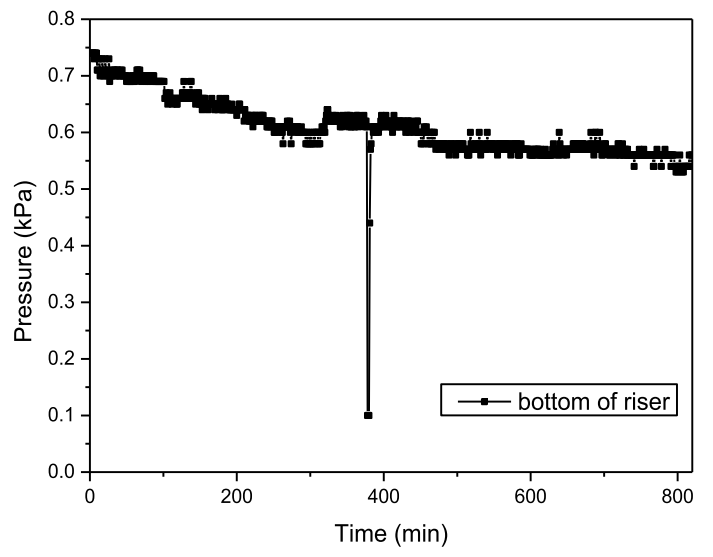

(b)

Fig. 2. Temperature and pressure distribution during preheating.

Table 4

Preheated coal gas composition.

\begin{tabular}{llllllllll}
\hline $\begin{array}{l}\mathrm{CO} \\
(\%)\end{array}$ & $\begin{array}{l}\mathrm{CO}_{2} \\
(\%)\end{array}$ & $\begin{array}{l}\mathrm{H}_{2} \\
(\%)\end{array}$ & $\begin{array}{l}\mathrm{CH}_{4} \\
(\%)\end{array}$ & $\begin{array}{l}\mathrm{N}_{2} \\
(\%)\end{array}$ & $\begin{array}{l}\mathrm{O}_{2} \\
(\%)\end{array}$ & $\begin{array}{l}\mathrm{NO} \\
(\mathrm{ppm})\end{array}$ & $\begin{array}{l}\mathrm{NO}_{2} \\
(\mathrm{ppm})\end{array}$ & $\begin{array}{l}\mathrm{N}_{2} \mathrm{O} \\
(\mathrm{ppm})\end{array}$ & $\begin{array}{l}\mathrm{LHV} \\
\left(\mathrm{MJ} / \mathrm{Nm}^{3}\right)\end{array}$ \\
\hline 8.27 & 14.23 & 9.15 & 2.86 & 58.49 & 0.00 & 0.00 & 0.00 & 0.00 & 3.06 \\
\hline
\end{tabular}

Note: LHV stands for lower heating value of coal gas.

combustions $[15,16]$. Therefore, the preheated coal gas of high-calorific value would contribute to the stable combustion of coarse coal particles, especially in the ignition phase. It should be noted that the concentrations of $\mathrm{NO}, \mathrm{NO}_{2}$ and $\mathrm{N}_{2} \mathrm{O}$ in the coal gas were all $0 \mathrm{ppm}$. According to our previous researches $[17,18]$, during the preheating, the fuel-nitrogen involved in the chemical reactions mainly existed in the forms of $\mathrm{NH}_{3}, \mathrm{HCN}$ and $\mathrm{N}_{2}$ due to the strong reducing atmosphere, and a considerable part of the released fuel-nitrogen were reduced to $\mathrm{N}_{2}$, which led to a partial denitrification in advance during the combustion.

Fig. 3 shows the coal particle size distribution before and after the preheating. After the preheating, the variations in $d_{50}$ and $d_{90}$ of coal particles were little, which varied from $0.118 \mathrm{~mm}$ and $0.386 \mathrm{~mm}$ to $0.121 \mathrm{~mm}$ and $0.380 \mathrm{~mm}$ respectively. However, the particle size distribution gone finer with the cumulative volume fraction below $50 \%$ or above $90 \%$ (the shadow in Fig. 3), which means that the proportion of the fine particles increased. The variation could improve the ignition and burnout characteristics of the coarse coal.

Fig. 4 shows the apparent topographical view of the single coal

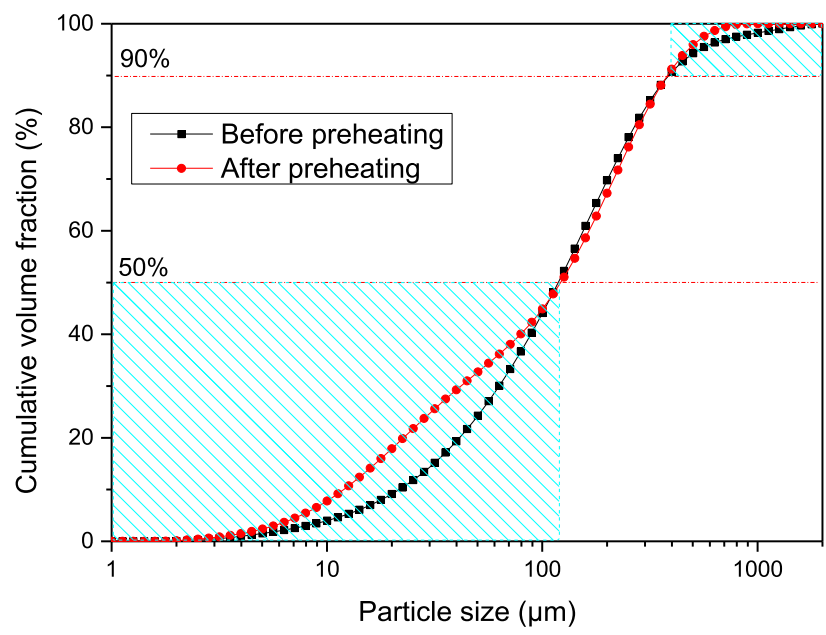

Fig. 3. Particle size distribution before and after preheating. particle magnified 300, 1000 and 1500 times before and after the preheating. It could be seen that the whole coal particle was not broken during the preheating, but the surface layer was obviously broken to fine particles attached to the surface. Therefore, the particle surface became rougher. The reason why the proportion of fine particles in the particle size distribution increased is more intuitively explained: on the one hand, it was due to the friction and collision between the coal particles or between the particles and the PCFB wall surface during the circulation; on the other hand, it was due to the oxidation reactions of active materials on the particle surface and the release of volatiles from the particle interior during the chemical reactions.

Furthermore, the BET theory was used to determine the particle surface area before and after the preheating. The result shows that the BET surface area reduced from $5.1994 \mathrm{~m}^{2} / \mathrm{g}$ to $4.0786 \mathrm{~m}^{2} / \mathrm{g}$ and the single point adsorption total pore volume of pores reduced from $10.188 * 10^{-3} \mathrm{~cm}^{3} / \mathrm{g}$ to $6.224 * 10^{-3} \mathrm{~cm}^{3} / \mathrm{g}$. Combined with the above results, it could be inferred that the pore structure partially collapsed during the oxidation of the surface active materials and the release of volatiles. The above variation reduced the contact area of oxygen with the coarse coal particle, which is detrimental to the ignition and burnout of the coarse coal.

Based on the principle of ash quality equilibrium during the preheating [19], we calculated the release ratio of each component in the coarse coal, and the results are summarized in Table 5 . It can be seen that approximately $33.31 \%$ of the fixed carbon and $82.49 \%$ of the volatiles participated in the chemical reactions during the preheating. The released heat partially maintained the preheating temperature of the PCFB, and the other part was used to enhance the physical sensible heat of the coal. As can be seen from Fig. 2, the fuel temperature was raised to above $750{ }^{\circ} \mathrm{C}$ after the preheating.

The ignition temperatures of the coarse coal and the preheated char were analyzed by the TG-DTG method on a thermogravimetric analyzer (STA 449 F3 NETZSCH) $[20,21]$. The results indicate that the ignition temperature was raised from $420{ }^{\circ} \mathrm{C}$ to $453{ }^{\circ} \mathrm{C}$ after the preheating. The reason for the increase in the ignition temperature was that most of the volatiles had been released, and the collapsed pore structure on particle surface was also not conducive to the ignition process [22]. Despite this, the temperature $\left(754{ }^{\circ} \mathrm{C}\right)$ of the preheated fuel was far above the ignition temperature $\left(453{ }^{\circ} \mathrm{C}\right)$ of the preheated char. Therefore, the assisted combustion by the high-calorific preheated coal gas and the higher physical sensible heat still allow the preheated fuel, including the preheated char, to reach a combustion state immediately in contact with the secondary air, which solved the difficulties in ignition encountered by utilizing coarse coal particles in conventional combustion techniques.

In addition, the release ratio of fuel-nitrogen during the preheating 

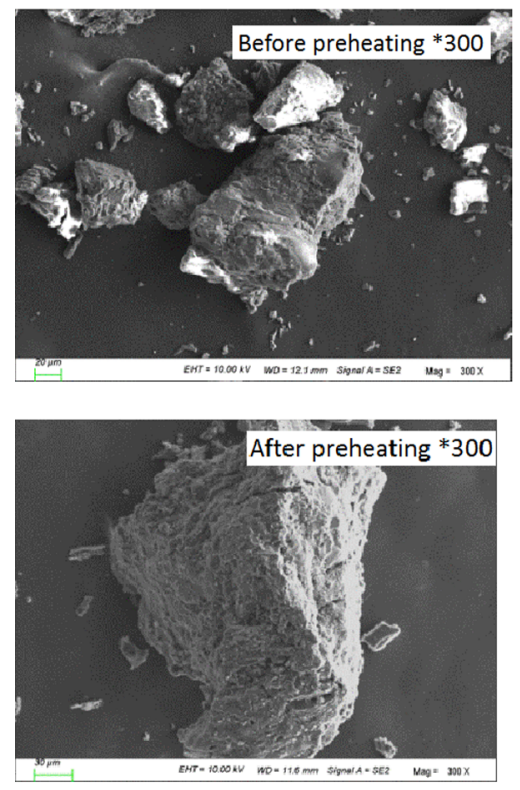
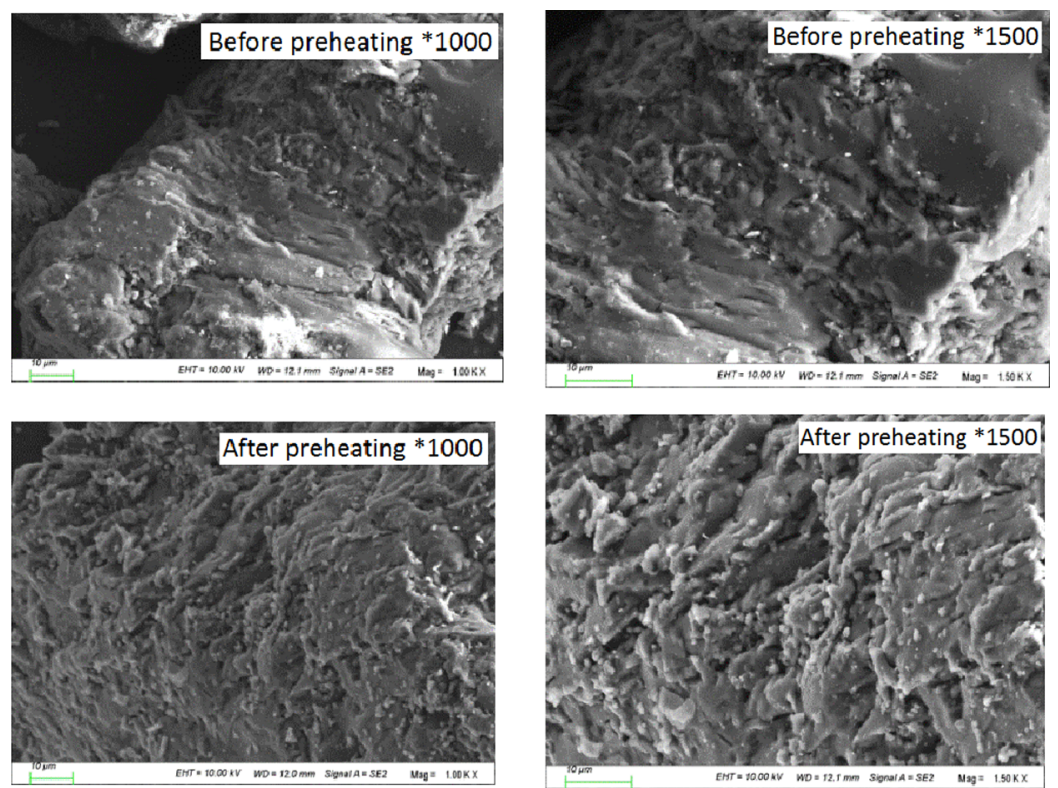

Fig. 4. SEM image of single particle surface before and after preheating.

Table 5

Analyses (wt.\%, air-dried) of preheated char particles.

\begin{tabular}{|c|c|c|c|c|c|c|c|c|c|}
\hline & \multicolumn{4}{|c|}{ Proximate analysis } & \multicolumn{5}{|c|}{ Ultimate analysis } \\
\hline & $M$ & $A$ & $V M$ & FC & $C$ & $H$ & $N$ & $S$ & $O^{\mathrm{a}}$ \\
\hline Value & 0 & 15.95 & 11.60 & 72.45 & 79.16 & 1.92 & 1.12 & 0.38 & 1.47 \\
\hline Release ratio (\%) & 100 & 0 & 82.49 & 33.31 & 47.29 & 81.25 & 36.56 & 39.01 & 87.82 \\
\hline
\end{tabular}

a By difference.

was approximately $36.56 \%$. Combined with the $\mathrm{NO}_{x}$ concentrations $(0 \mathrm{ppm})$ in the preheated coal gas, it is verified again that the predenitrogenation process during the preheating is a key to achieve low$\mathrm{NO}_{x}$ emissions in the coarse coal combustion. Also, it should be noted that the remaining fuel-nitrogen in the preheated char was above $60 \%$. Therefore, the fuel-nitrogen migration and transformation in the post main combustion zone also need to be in-depth clarified to further reduce $\mathrm{NO}_{x}$ emissions.

The X-ray photoelectron spectroscopy (XPS) method was adopted to analyze the nitrogen-containing functional groups on the coal particle surface before and after the preheating. The results are shown in Fig. 5. The nitrogen-containing functional groups on the particle surface are

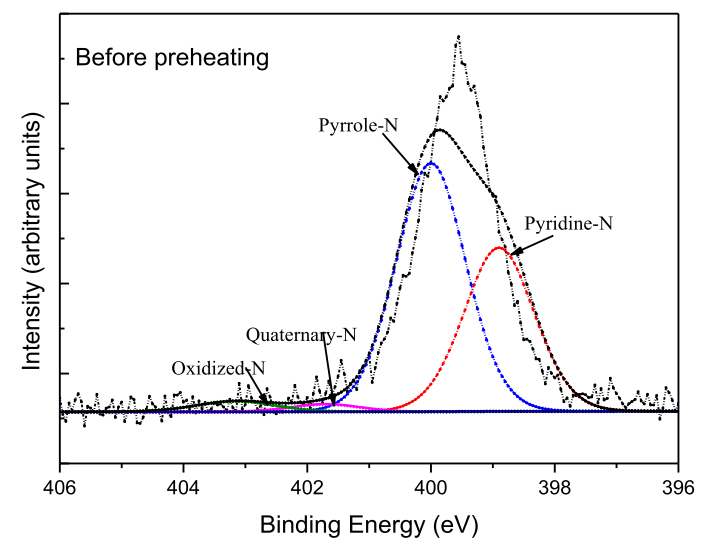

divided into four types: pyrrole-N (N-5), pyridine-N (N-6), quaternary$\mathrm{N}(\mathrm{N}-\mathrm{Q})$, and oxidized-N (N-X) $[23,24]$. The ring structure of $\mathrm{N}-5$ is fivemembered, while the ring structure of $\mathrm{N}-6$ and $\mathrm{N}-\mathrm{Q}$ is six-membered. It can be seen that the ratio of $\mathrm{N}-5 /(\mathrm{N}-6+\mathrm{N}-\mathrm{Q})$ increased from 1.44 to 3.36 during the preheating, which indicates that the six-membered nitrogen-containing functional groups were converted to the fivemembered, especially the relative proportion of the N-Q decreased to 0 . It is important to note that the $\mathrm{N}-\mathrm{Q}$ is the main source of the ammonia $\left(\mathrm{NH}_{3}\right)$ release [25]. Besides, the $\mathrm{N}-\mathrm{X}$ is easy to break down to $\mathrm{NO}_{\mathrm{x}}$ [26], and the relative proportion of the $\mathrm{N}-\mathrm{X}$ increased from $2.78 \%$ to $11.80 \%$ during the preheating, which indicates that the residual fuel-nitrogen in the preheated char was more easily released and converted into $\mathrm{NO}_{x}$ in the PCC. Therefore, inhibiting the $\mathrm{NO}_{x}$ formation in the PCC is critical to achieving low- $\mathrm{NO}_{x}$ emissions. It is verified again that the research on the nitrogen migration and transformation path in the PCC is necessary.

\subsection{Combustion characteristics in PCC}

Based on the stable preheating of the coarse coal, the combustion characteristics and $\mathrm{NO}_{x}$ emission characteristics of the preheated fuel were studied here.

\subsubsection{Temperature distribution}

Fig. 6 shows the long-term operating temperature profile at

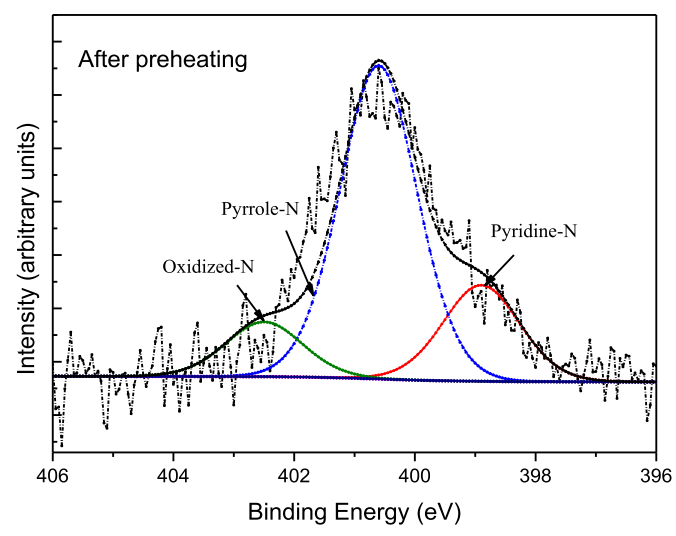

Fig. 5. XPS nitrogen (1s) spectra before and after preheating. 

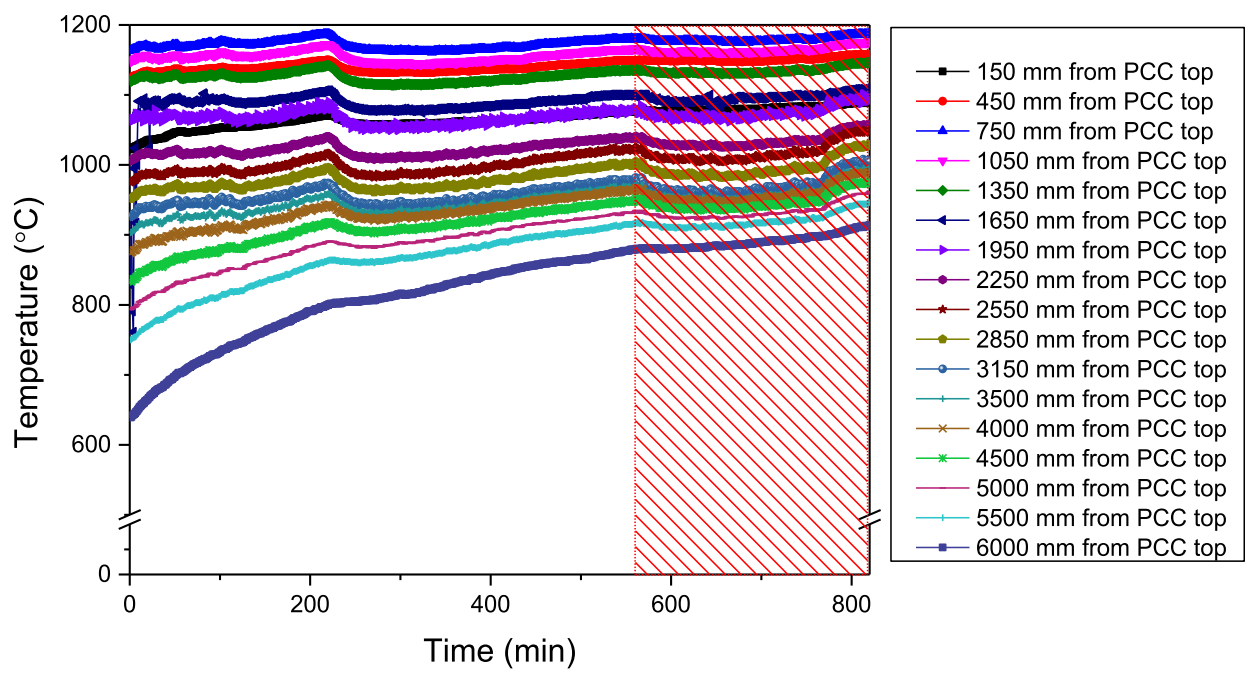

Fig. 6. Temperature distribution during combustion.

different locations along the PCC. The time required for reaching the stable temperature in the zone farther from the PCC top was later than that in the zone near the PCC top, because the PCC wall surface is made of refractory material, which required a slow heat-storage process to reach a stable temperature. The research data on the combustion characteristics of the preheated fuel is more reliable only when the temperature in the entire combustion chamber reaches equilibrium.

Fig. 7 displays the stable temperature distribution along the combustion path. The burnout air was injected at the locations of $300 \mathrm{~mm}$, $1200 \mathrm{~mm}, 2400 \mathrm{~mm}$ and $3000 \mathrm{~mm}$ below the PCC top respectively, so the zone between the top and the location of $3000 \mathrm{~mm}$ below the top is defined as the main combustion zone, and the zone between the location of $3000 \mathrm{~mm}$ below the top and the bottom is defined as the burnout zone. As can be seen from Fig. 7, the coarse coal achieved a stable ignition and combustion by preheating fuel in the PCFB. The maximum temperature in the main combustion zone was approximately $1178^{\circ} \mathrm{C}$, and the temperature difference $\left(\Delta T_{1}\right)$ in this zone was only within $175{ }^{\circ} \mathrm{C}$. It indicates that there was no local high-temperature zone (above $1500{ }^{\circ} \mathrm{C}$ ) in the high-temperature preheated fuel combustion, which inhibited the generation of thermal-NO [27]. In addition, the temperature difference $\left(\Delta T_{2}\right)$ in the combustion chamber was within $280^{\circ} \mathrm{C}$. In order to express the combustion intensity and the combustion reaction uniformity in the PCC more clearly, we introduced the volumebased average temperature $\left(T_{\text {mean-v }}\right)$ and the dimensionless volumebased temperature fluctuation coefficient $\left(T^{\prime}\right)$ :

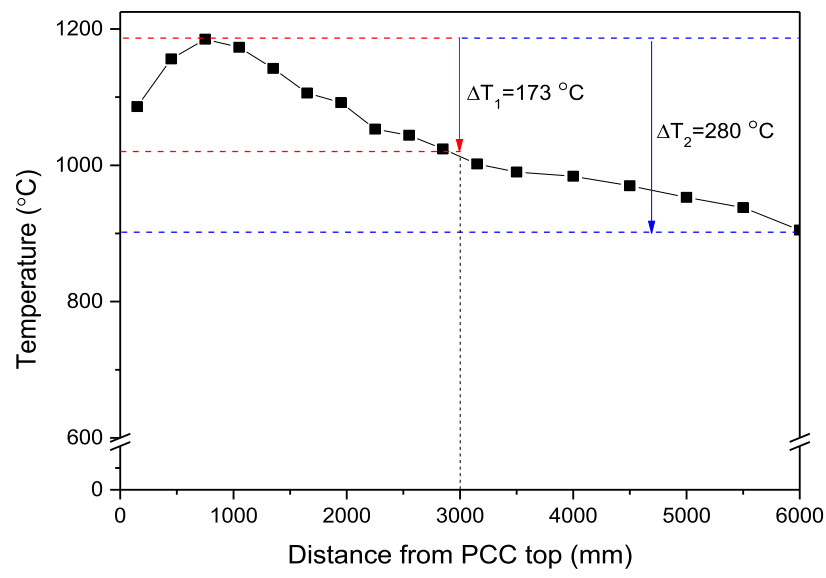

Fig. 7. Temperature distribution along combustion path.
$T_{\text {mean-V }}=\frac{\int T \mathrm{~d} V}{\int \mathrm{d} V}$

$T^{\prime}=\left(\frac{\int\left(\frac{T-T_{\text {mean }}}{T_{\text {mean }}}\right)^{2} \mathrm{~d} V}{\int \mathrm{d} V}\right)^{0.5}$

The calculation results show that the volume-based average temperatures in the main combustion zone $\left(T_{\text {mean-v1 }}\right)$ and the entire combustion zone ( $\left.T_{\text {mean-V2 }}\right)$ was approximately $1112{ }^{\circ} \mathrm{C}$ and $1034{ }^{\circ} \mathrm{C}$, while the volume-based temperature fluctuation coefficient in the main combustion zone $\left(T^{\prime}{ }_{1}\right)$ and the entire combustion zone $\left(T^{\prime}{ }_{2}\right)$ were approximately $8.89 \%$ and $7.91 \%$. According to Kumar's research [28], the volume-based temperature fluctuation coefficient of conventional turbulent combustion can be as high as $51 \%$, while the combustion mode is converted to the MILD combustion when the fluctuation coefficient is less than $15 \%$. In this MILD combustion mode, the more uniform temperature field is beneficial for the reduction of $\mathrm{NO}_{x}$.

During the stable operation, the tail fly ash was sampled to calculate the combustion efficiency of the coarse coal $[29,30]$. The result indicates that the combustion efficiency was approximately $95 \%$. Compared to the combustion efficiency (above 98\%) of the fine coal in the previous study [14], the combustion efficiency in this study was lower. With the particle size going coarser, the total specific surface area of the coal particles became smaller, and the diffusion resistance of oxygen in the coal particles became larger, which resulted in a reduction in the reaction area and an increase in the burnout time. And the carbon particles in the particle center could not be burned out and a black core appeared, which led to a reduction in the combustion efficiency.

\subsubsection{Nitrogen conversion}

Eight flue gas sampling ports are arranged at the locations of $750 \mathrm{~mm}, 1950 \mathrm{~mm}, 2550 \mathrm{~mm}, 3150 \mathrm{~mm}, 3750 \mathrm{~mm}, 4950 \mathrm{~mm}$, $5550 \mathrm{~mm}$ and $6000 \mathrm{~mm}$ below the PCC top. The gas concentrations in the flue gas are online measured by the Gasmet FTIR DX-4000 analyzer and the oxygen concentration in the flue gas is online measured by the zirconia oxygen analyzer.

Fig. 8 shows the nitrogen-containing gas concentrations $\left(\mathrm{NO}, \mathrm{N}_{2} \mathrm{O}\right.$, $\mathrm{NH}_{3}$, and $\mathrm{HCN}$ ) and $\mathrm{CO}$ concentration distribution along the combustion path in the PCC, where SA, BA-1, BA-2, BA-3, and BA-4 are on behalf of the secondary air, the burnout air at the four locations along the combustion path. An uncertainty and error analysis is important for the experiment $[31,32]$. In Fig. 8, we use the form of error bars to more intuitively represent the true gas concentration measured at stable operating time. As can be seen from Fig. 8 that the nitrogen-containing 

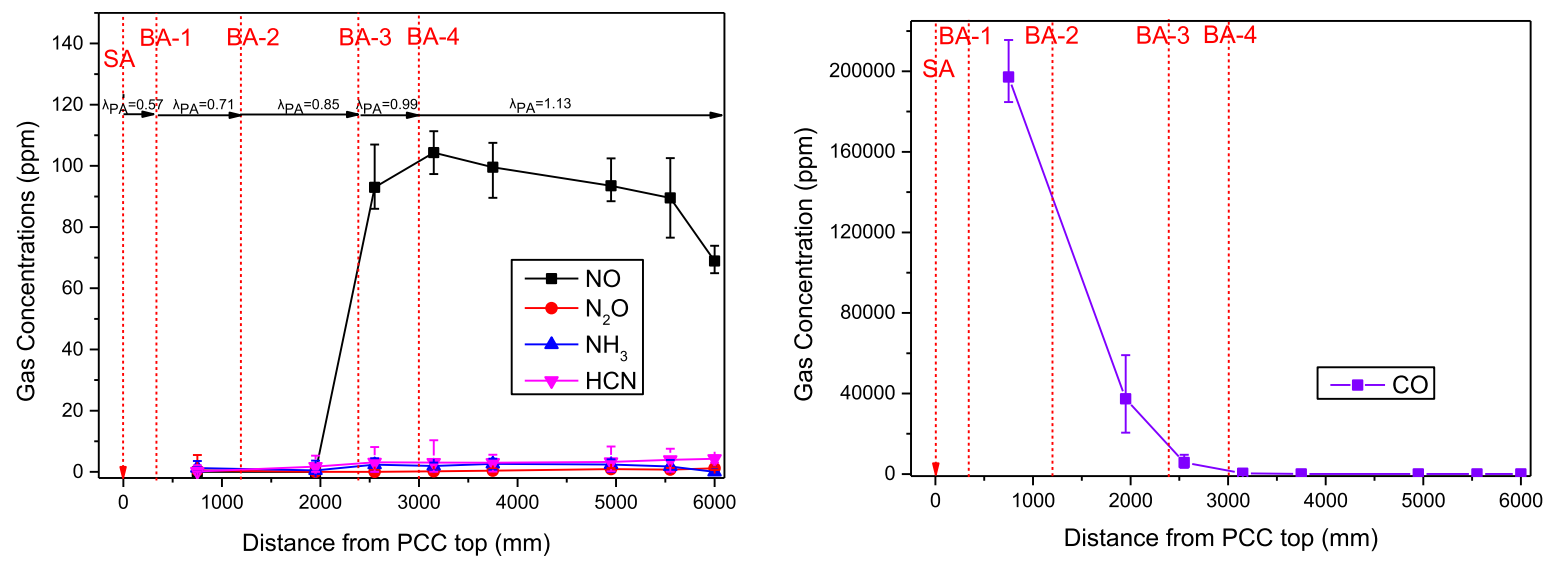

Fig. 8. Gas concentration distribution along combustion path.

gas in the PCC were mainly present in the forms of $\mathrm{NO}$ and $\mathrm{N}_{2}$. The redox reactions of $\mathrm{NO}_{x}$ are a combination of reactions in the gas-gas phase and gas-solid phase [27]. In the main combustion zone, the variation in the $\mathrm{NO}_{x}$ concentration was determined by the redox reactions in gas-gas phase due to its extremely fast chemical reaction rate compared to the reactions in gas-solid phase. When the secondary air and the first-stage burnout air were injected, the high-temperature preheated coal gas quickly consumed most oxygen, and the volatiles released from the preheated char also reacted quickly with the remaining oxygen, which created a strong reducing atmosphere in the PCC entrance zone. Furthermore, the air-equivalent ratio in the zone between the injection locations of first-stage and second-stage burnout air was approximately 0.71 , where the $\mathrm{CO}$ concentration was as high as $19.71 \%$, indicating that the zone was still in a strong reducing atmosphere. Therefore, the $\mathrm{NO}_{x}$ concentrations in these zones were almost $0 \mathrm{ppm}$. Combined with the analysis on nitrogen-containing gas in the preheated coal gas, we infer that the main nitrogen-containing intermediates such as $\mathrm{NH}_{3}$ and $\mathrm{HCN}$ were converted to $\mathrm{N}_{2}$ by the reductive reactions with $\mathrm{CO}, \mathrm{H}_{2}$ or $\mathrm{CH}_{\mathrm{i}}$ at the temperature range of $1000-1200{ }^{\circ} \mathrm{C}$ under the catalytic conditions of char in these zones. And the released fuel-nitrogen was also reduced to $\mathrm{N}_{2}$, the related reactions could be summarized as followed [27]:

$\mathrm{C}(\mathrm{N})+\mathrm{O}_{2} \rightarrow \mathrm{NO}+\mathrm{C}(\mathrm{O})$

$2 \mathrm{C}_{f}+\mathrm{O}_{2} \rightarrow \mathrm{C}^{\prime}(\mathrm{N})+\mathrm{C}(\mathrm{O})$

$\mathrm{C}^{\prime}(\mathrm{N})+\mathrm{NO} \rightarrow \mathrm{N}_{2}+\mathrm{C}(\mathrm{O})$

where $\mathrm{C}(\mathrm{N})$ and $\mathrm{C}(\mathrm{O})$ represent nitrogen and oxygen species on the char surface repectively, $\mathrm{C}_{f}$ represents a free carbon site, while $\mathrm{C}^{\prime}(\mathrm{N})$ represents a different nitrogen surface species.

With the grading injection of the burnout air, the reaction atmosphere gradually varied from a reducing atmosphere to an oxidizing atmosphere, and the $\mathrm{CO}$ concentration was greatly reduced. Meanwhile, fuel-nitrogen in the preheated char was mainly oxidized to NO. When the third-stage burnout air was injected, the remaining other nitrogen-containing gas concentrations were extremely low, and they could be ignored compared to the $\mathrm{NO}$ and $\mathrm{N}_{2}$ concentrations. In the burnout combustion zone, there was a slow decline in the NO concentration, because the reductive reactions of $\mathrm{NO}_{x}$ occurred mainly at the char surface [12].

Fig. 9 shows the gas concentrations $\left(\mathrm{NO}, \mathrm{N}_{2} \mathrm{O}, \mathrm{NH}_{3}, \mathrm{HCN}, \mathrm{CO}\right.$ and $\mathrm{O}_{2}$ ) distribution along time in the flue gas. As can be seen from Fig. 9, the $\mathrm{CO}$ emissions in the flue gas were only $26 \mathrm{ppm}$. In addition, the main nitrogen-containing gas after complete combustion was NO, and the other nitrogen-containing gas $\left(\mathrm{N}_{2} \mathrm{O}, \mathrm{NH}_{3}, \mathrm{HCN}\right)$ concentrations were extremely low. The time-based average value of the NO emissions was approximately $68 \mathrm{ppm}$, which was also a $\mathrm{NO}_{x}$ concentration of
$114 \mathrm{mg} / \mathrm{m}^{3}$ (@6\% $\mathrm{O}_{2}$ ). Compared to the original $\mathrm{NO}_{x}$ emissions (400-600 mg/m $\mathrm{m}^{3} @ 6 \% \mathrm{O}_{2}$ ) in other low- $\mathrm{NO}_{x}$ combustion technologies [33-36], the original NO emission in this study was lower. It indicates that the preheating combustion technology realizes the stable low- $\mathrm{NO}_{x}$ combustion of coarse coal.

\subsection{Effects of burnout air distribution}

In this section, the effects of burnout air distribution on the combustion characteristics and NO emissions were discussed, where only the injecting positions of the burnout air in strong reductive zone were varied. The detailed arrangements are summarized in Table 6 .

Fig. 10 shows the temperature distribution along the combustion path with different burnout air positions. In the combustion zone of $0-450 \mathrm{~mm}$ below the PCC top, the temperature in case 1 was higher than other cases. It is due to the advanced oxidation reactions between the preheated fuel and the first-stage burnout air. With the BA-2 position moving down, the temperature in the burnout zone became higher. In general, the variations in the combustion temperature were consistent with the variations in the combustion share.

In order to quantitatively analyze the effects of burnout air positions on combustion characteristics, the volume-based average temperatures and volume-based temperature fluctuation coefficient in the main combustion zone $\left(T_{\text {mean-v1 }}\right.$ and $\left.T^{\prime}{ }_{1}\right)$ and the entire combustion zone $\left(T_{\text {mean-v2 }}\right.$ and $\left.T^{\prime}{ }_{2}\right)$ are displayed in Fig. 11 . As the burnout air positions moved down, the $T_{\text {mean-v1 }}$ and $T_{\text {mean-v2 }}$ both gradually increased, while the $T^{\prime}{ }_{1}$ and $T^{\prime}{ }_{2}$ varied little, which means that the combustion reactions were stable all the time. Because the BA- 1 and BA- 2 positions were arranged in the strong reducing atmosphere, the injected oxygen was quickly consumed to react with fuel, which released chemical heat. Meanwhile, the reaction time of the char particles in the strong reducing atmosphere increased when the BA- 1 and BA-2 positions moved down. Therefore, the diameter of the carbon core would decrease and the specific surface area would increase accordingly. As the combustion atmosphere along the combustion path was varied from reducing to oxidizing, the combustion reactions between the smaller carbon core and the burnout air became more intense, and the amount of heat released increased, which resulted in an increase in the volume-based temperature. As a result, the combustion efficiency is slightly increased.

Fig. 12 shows the NO emissions with different burnout air positions. The result indicates that the NO emissions were almost same in all cases. Even if the volume-based average temperature gradually increased, the temperature was far below the $1500{ }^{\circ} \mathrm{C}$ and the temperature variation (approximately $30{ }^{\circ} \mathrm{C}$ ) was still small. Furthermore, the temperature fluctuation coefficient varied little, which avoided the high-temperature region that promoted NO generation. In the strong reducing atmosphere where BA- 1 and BA- 2 positions were varied, the fuel-nitrogen conversion path kept unchanged. The results indicate that 


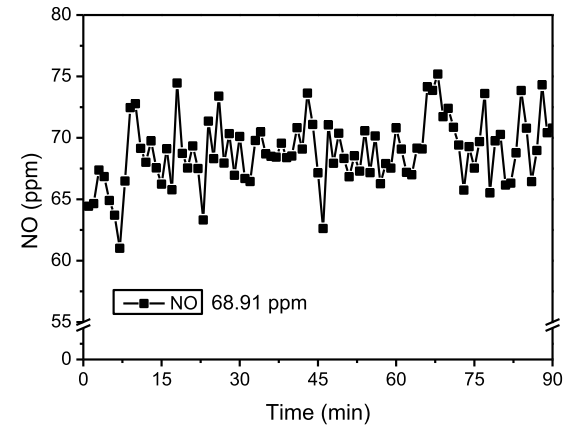

(a) NO distribution

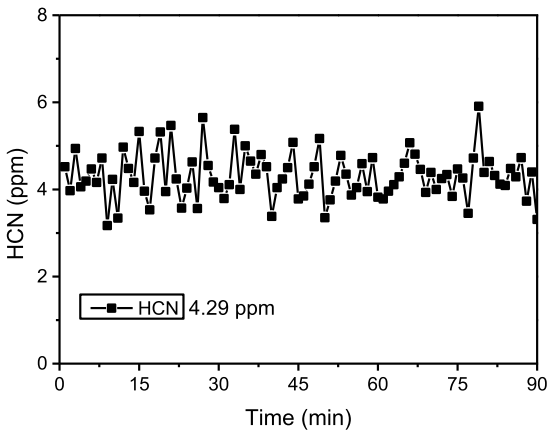

(d) $\mathrm{HCN}$ distribution

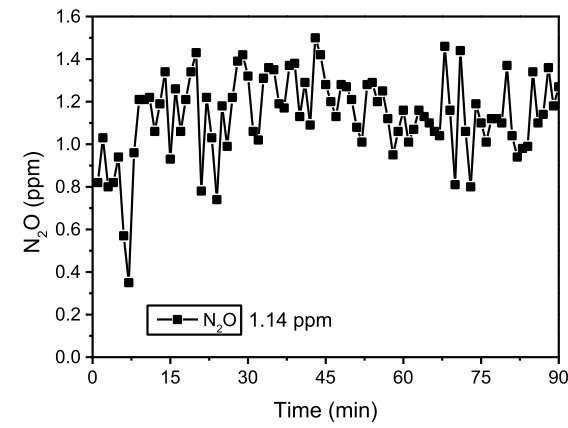

(b) $\mathrm{N}_{2} \mathrm{O}$ distribution

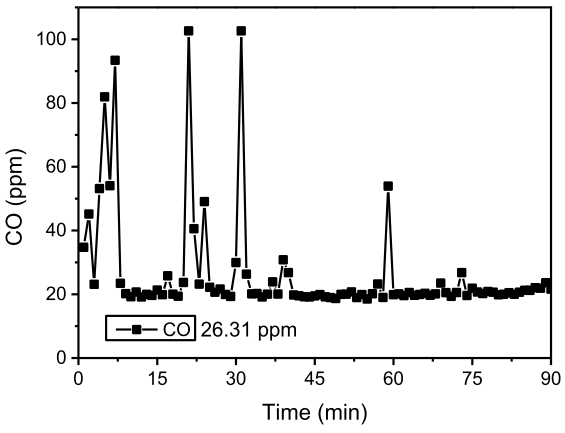

(e) $\mathrm{CO}$ distribution

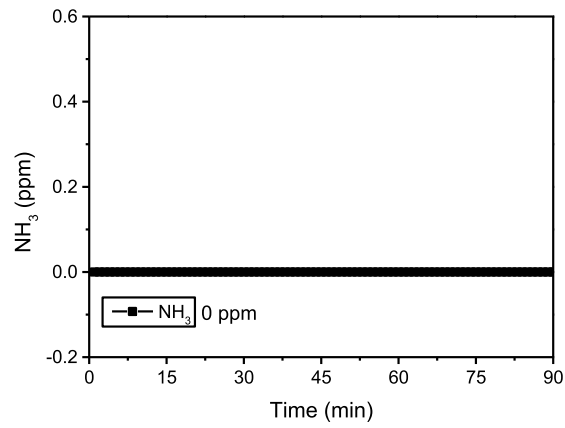

(c) $\mathrm{NH}_{3}$ distribution

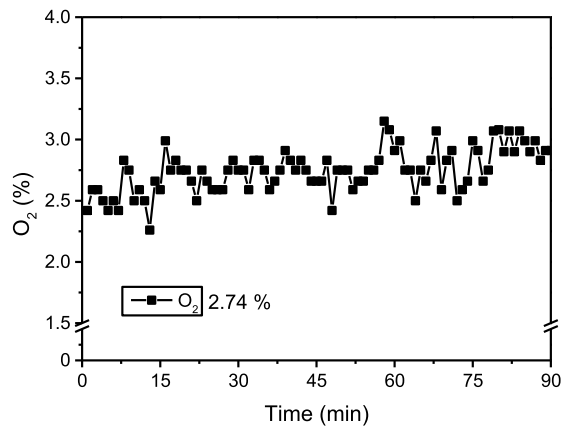

(f) $\mathrm{O}_{2}$ distribution

Fig. 9. Gas concentration distribution in flue gas.

Table 6

Burnout air position arrangement.

\begin{tabular}{lllll}
\hline & \multicolumn{2}{l}{ Distance from PCC top $(\mathrm{mm})$} & & \\
\cline { 2 - 5 } & BA-1 & BA-2 & BA-3 & BA-4 \\
\hline Case 1 & 300 & 1200 & 2400 & 3000 \\
Case 2 & 900 & 1200 & & \\
Case 3 & 900 & 1500 & & \\
Case 4 & 900 & 1800 & & \\
\hline
\end{tabular}

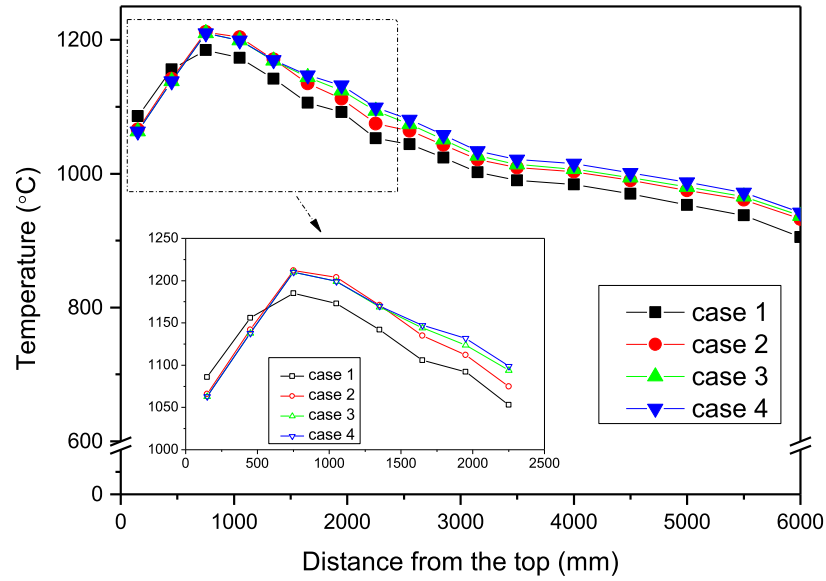

Fig. 10. Temperature distribution with different burnout air positions.

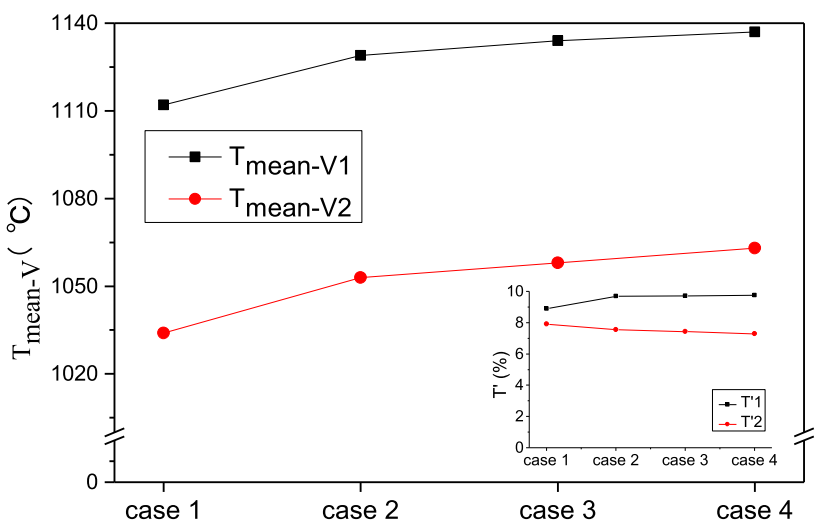

Fig. 11. . Temperature distribution with different burnout air positions.

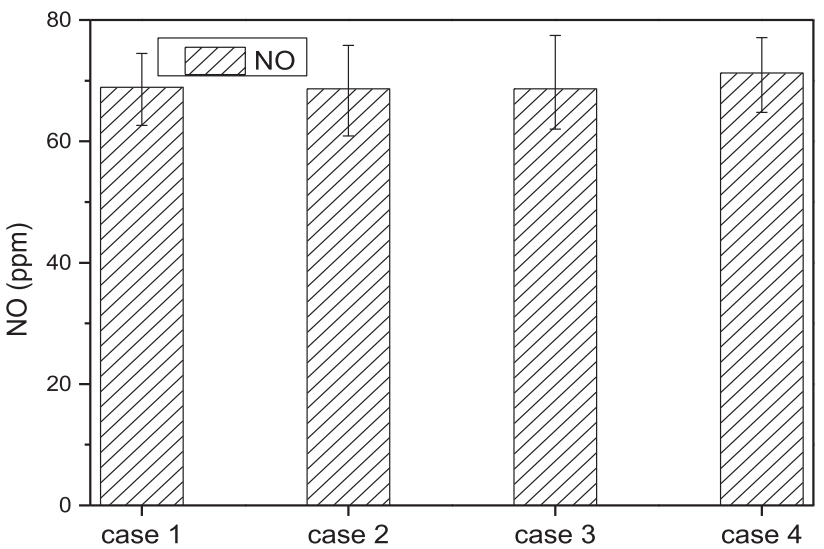

Fig. 12. NO emissions with different burnout air positions. 
the effects of burnout air positions in strong reductive zone on NO emission could be ignored.

\section{Conclusions}

The coarse coal could achieve a long-term stable preheating. During the preheating, the surface layer was obviously broken to fine particles attached to the surface, and the pore structure partially collapsed, which reduced the contact area of oxygen with the coarse coal particle. However, the assisted combustion by the high-calorific preheated coal gas $\left(3.06 \mathrm{MJ} / \mathrm{Nm}^{3}\right)$ and the higher physical sensible heat $\left(754{ }^{\circ} \mathrm{C}\right)$ still allow the preheated fuel to reach a combustion state immediately in contact with the secondary air, which solved the ignition difficulties in coarse coal combustion.

Meanwhile, the release ratio of fuel-nitrogen during the preheating was $36.56 \%$, while the concentrations of $\mathrm{NO}, \mathrm{NO}_{2}$ and $\mathrm{N}_{2} \mathrm{O}$ in the preheated coal gas were all $0 \mathrm{ppm}$. The fuel-nitrogen involved in the preheating chemical reactions mainly existed in the forms of $\mathrm{NH}_{3}, \mathrm{HCN}$ and $\mathrm{N}_{2}$ due to the strong reducing atmosphere, and a considerable part of the released fuel-nitrogen were reduced to $\mathrm{N}_{2}$, which led to a partial denitrification in advance during the combustion.

After the preheating, the coarse coal could achieve a stable ignition and combustion. There was no local high-temperature zone (above $1500{ }^{\circ} \mathrm{C}$ ) during the preheated fuel combustion. The volume-based average temperature and the volume-based temperature fluctuation coefficient in the main combustion zone was approximately $1112{ }^{\circ} \mathrm{C}$ and $8.89 \%$, which indicates that the combustion was in the MILD combustion mode. The combustion efficiency was approximately $95 \%$.

The $\mathrm{NO}_{x}$ concentrations in the strong reducing atmosphere of $0-2400 \mathrm{~mm}$ below the PCC top were almost $0 \mathrm{ppm}$. As the reaction atmosphere gradually varied from reducing to oxidizing, fuel-nitrogen in the preheated char was mainly oxidized to NO, and the NO emissions were $68 \mathrm{ppm}\left(114 \mathrm{mg} / \mathrm{m}^{3} @ 6 \% \mathrm{O}_{2}\right)$. When the burnout air positions in the strong atmosphere moved down, the NO emissions were almost same in all cases. Overall, the preheating combustion technology realizes the stable low- $\mathrm{NO}_{x}$ combustion of coarse coal.

The results have proven a new feasible approach for coarse coal combustion in pulverized coal boilers, and could provide theoretical guidance for future engineering applications. In the future research, we will explore to increase the combustion efficiency of the coarse coal by enhancing the mix of the high-temperature preheated fuel and the secondary air, and increasing the combustion temperature (below $\left.1300{ }^{\circ} \mathrm{C}\right)$.

\section{CRediT authorship contribution statement}

Shujun Zhu: Conceptualization, Methodology, Validation, Formal analysis, Investigation, Data curation, Writing - original draft, Writing review \& editing, Funding acquisition. Jianguo Zhu: Project administration, Conceptualization, Methodology, Funding acquisition. Qinggang Lyu: Supervision, Conceptualization, Methodology. Jingzhang Liu: Investigation. Ziqu Ouyang: Investigation.

\section{Declaration of Competing Interest}

The authors declare that they have no known competing financial interests or personal relationships that could have appeared to influence the work reported in this paper.

\section{Acknowledgments}

The authors gratefully acknowledge the supports of the National Natural Science Foundation of China (No. 51676187), the LHD Youth Innovation Fund of State Key Laboratory of High Temperature Gas Dynamics (LHD2019CX08), and the Postdoctoral Funding Project for the Construction of Highly Sophisticated Engineering Disciplines of University of Chinese Academy of Sciences.

\section{References}

[1] Kan S, Chen B, Chen G. Worldwide energy use across global supply chains: decoupled from economic growth? Appl Energy 2019;250:1235-45.

[2] Wang Q, Chen Z, Chen Q, Zeng L, Li Z. Experimental investigation of gas/particle two-phase flow characteristics in a down-fired boiler by PDA measurements. Exp Therm Fluid Sci 2019;107:38-53.

[3] Zeng L, Song M, Li X, Liu Y, Li Z, Chen Z. Factors affecting the downward flame depth in a 600MW down-fired boiler incorporating multiple-injection and multiplestaging technology. Energy 2017;118:333-44.

[4] Gu M, Chen X, Wu C, He X, Chu H, Liu F. Effects of particle size distribution and oxygen concentration on the propagation behavior of pulverized coal flames in $\mathrm{O}_{2} /$ $\mathrm{CO}_{2}$ atmospheres. Energy Fuels 2017;31(5):5571-80.

[5] Zhang J, Wang C, Jia X, Wang P, Che D. Experimental study on combustion and NO formation characteristics of semi-coke. Fuel 2019;258:116108.

[6] Lu J, Chen L, Shen J, Wu Y, Lu F. A study of control strategy for the bin system with tube mill in the coal fired power station. ISA Trans 2002;41(2):215-24.

[7] Pronobis M, Mroczek K, Tymoszuk M, Ciukaj S, Wejkowski R, Janda T, et al. Optimisation of coal fineness in pulverised-fuel boilers. Energy 2017;139:655-66.

[8] Shi X, Nenes A, Xiao Z, Song S, Yu H, Shi G, et al. High-resolution data sets unravel the effects of sources and meteorological conditions on nitrate and its gas-particle partitioning. Environ Sci Technol 2019;53(6):3048-57.

[9] Saha M, Dally BB, Chinnici A, Medwell PR. Effect of co-flow oxygen concentration on the MILD combustion of pulverised coal. Fuel Process Technol 2019;193:7-18.

[10] Perrone D, Castiglione T, Klimanek A, Morrone P, Amelio M. Numerical simulations on Oxy-MILD combustion of pulverized coal in an industrial boiler. Fuel Process Technol 2018;181:361-74.

[11] Kamal M. Parametric study of combined premixed and non-premixed flame coal burner. Fuel 2008;87(8-9):1515-28.

[12] Zhu S, Lyu Q, Zhu J, Wu H, Wu G. Effect of air distribution on $\mathrm{NO}_{x}$ emissions of pulverized coal and char combustion preheated by a circulating fluidized bed. Energy Fuels 2018;32(7):7909-15.

[13] Zhu S, Lyu Q, Zhu J, Liang C. Experimental study on $\mathrm{NO}_{x}$ emissions of pulverized bituminous coal combustion preheated by a circulating fluidized bed. J Energy Inst 2019;92(2):247-56.

[14] Man C, Zhu J, Ouyang Z, Liu J, Lyu Q. Experimental study on combustion characteristics of pulverized coal preheated in a circulating fluidized bed. Fuel Process Technol 2018;172:72-8.

[15] Nicolaia H, Kuennea G, Knappsteina R, Schneiderb H, Beckerb LG, Hassec C, et al Large Eddy Simulation of a laboratory-scale gas-assisted pulverized coal combustion chamber under oxy-fuel atmospheres using tabulated chemistry. Fuel 2020;272:117683.

[16] Becker L, Pielsticker S, Böhm B, Kneer R, Dreizl A. Particle dynamics in a gas assisted coal combustion chamber using advanced laser diagnostics. Fuel 2020;269:117188.

[17] Zhu S, Lyu Q, Zhu J. Experimental investigation of $\mathrm{NO}_{x}$ emissions during pulverized char combustion in oxygen-enriched air preheated with a circulating fluidized bed. J Energy Inst 2019;92(5):1388-98.

[18] Zhu S, Lyu Q, Zhu J, Wu H, Fan Y. Low $\mathrm{NO}_{x}$ emissions from pulverized coal moderate or intense low-oxygen dilution combustion in $\mathrm{O}_{2} / \mathrm{CO}_{2}$ preheated by a circulating fluidized bed. Energy Fuels 2018;32(10):10956-63.

[19] Ouyang Z, Zhu J, Lu Q. Experimental study on preheating and combustion characteristics of pulverized anthracite coal. Fuel 2013;113:122-7.

[20] Kok MV, Özgür E. Thermal analysis and kinetics of biomass samples. Fuel Process Technol 2013;106:739-43.

[21] Qing W, Chunxia J, Qianqian J, Yin W, Wu D. Combustion characteristics of Indonesian oil sands. Fuel Process Technol 2012;99:110-4.

[22] Cheng J, Wang X, Si T, Zhou F, Zhou J, Cen K. Pore fractal structures and combustion dynamics of cokes derived from the pyrolysis of typical Chinese power coals. Fuel Process Technol 2016;149:49-54.

[23] Wang Q, Pan S, Bai J, Chi M, Cui D, Wang Z, et al. Experimental and dynamics simulation studies of the molecular modeling and reactivity of the Yaojie oil shale kerogen. Fuel 2018;230:319-30.

[24] Xu M, Li S, Wu Y, Jia L, Lu Q. Effects of $\mathrm{CO}_{2}$ on the fuel nitrogen conversion during coal rapid pyrolysis. Fuel 2016;184:430-9.

[25] Zhang H, Fletcher TH. Nitrogen transformations during secondary coal pyrolysis. Energy Fuels 2001;15(6):1512-22.

[26] Kelemen SR, Afeworki M, Gorbaty ML, Sansone M, Kwiatek PJ, Walters CC, et al. Direct characterization of Kerogen by X-ray and solid-state 13C nuclear magnetic resonance methods. Energy Fuels 2007;21(3):1548-61.

[27] Glarborg P, Jensen AD, Johnsson JE. Fuel nitrogen conversion in solid fuel fired systems. Prog Energy Combust Sci 2003;29(2):89-113.

[28] Kumar S, Paul PJ, Mukunda HS. Studies on a new high-intensity low-emission burner. Proc Combust Inst 2002;29:1131-7.

[29] Lu Q, Zhu J, Niu T, Song G, Na Y. Pulverized coal combustion and $\mathrm{NO}_{x}$ emissions in high temperature air from circulating fluidized bed. Fuel Process Technol 2008;89(11):1186-92.

[30] Zhu J, Lu Q, Niu T, Song G, Na Y. NO emission on pulverized coal combustion in high temperature air from circulating fluidized bed - an experimental study. Fuel Process Technol 2009;90(5):664-70.

[31] Acar M, Erbas O, Arslan O. The performance of vapor compression cooling system 
aided Ranque-Hilsch vortex tube. Therm Sci 2019;23:1189-201.

[32] Arslan O. ANN-based determination of optimum working conditions of residential combustors with respect to optimum insulation. Energy Sources 2014;36(23):2603-12.

[33] Kuang M, Li Z, Zhang Y, Chen X, Jia J, Zhu Q. Asymmetric combustion characteristics and $\mathrm{NO}_{x}$ emissions of a down-fired 300MWe utility boiler at different boiler loads. Energy. 2012;37(1):580-90.

[34] Li Z, Liu G, Zhu Q, Chen Z, Ren F. Combustion and $\mathrm{NO}_{x}$ emission characteristics of a retrofitted down-fired 660 MWe utility boiler at different loads. Appl Energy
2011;88(7):2400-6.

[35] Wang Q, Chen Z, Li L, Zeng L, Li Z. Achievement in ultra-low-load combustion stability for an anthracite- and down-fired boiler after applying novel swirl burners: from laboratory experiments to industrial applications. Energy. 2019;116623.

[36] Wang Q, Chen Z, Han H, Zeng L, Li Z. Experimental characterization of anthracite combustion and $\mathrm{NO}_{x}$ emission for a 300-MWe down-fired boiler with a novel combustion system: Influence of primary and vent air distributions. Appl Energy 2019;238:1551-62. 